\title{
Notes on the vocalizations of Masked Yellowthroat (Geothlypis aequinoctialis)
}

Peter Boesman

In the following we briefly analyze and compare voice of the different races of Masked Yellowthroat (Geothlypis aequinoctialis). We also try to quantify the extent of any vocal differences using the criteria proposed by Tobias et al. (2010), as a support for taxonomic review. We have made use of sound recordings available on-line from Xeno Canto (XC).

G. a. chiriquensis (S Costa Rica and adjacent SW Panama)
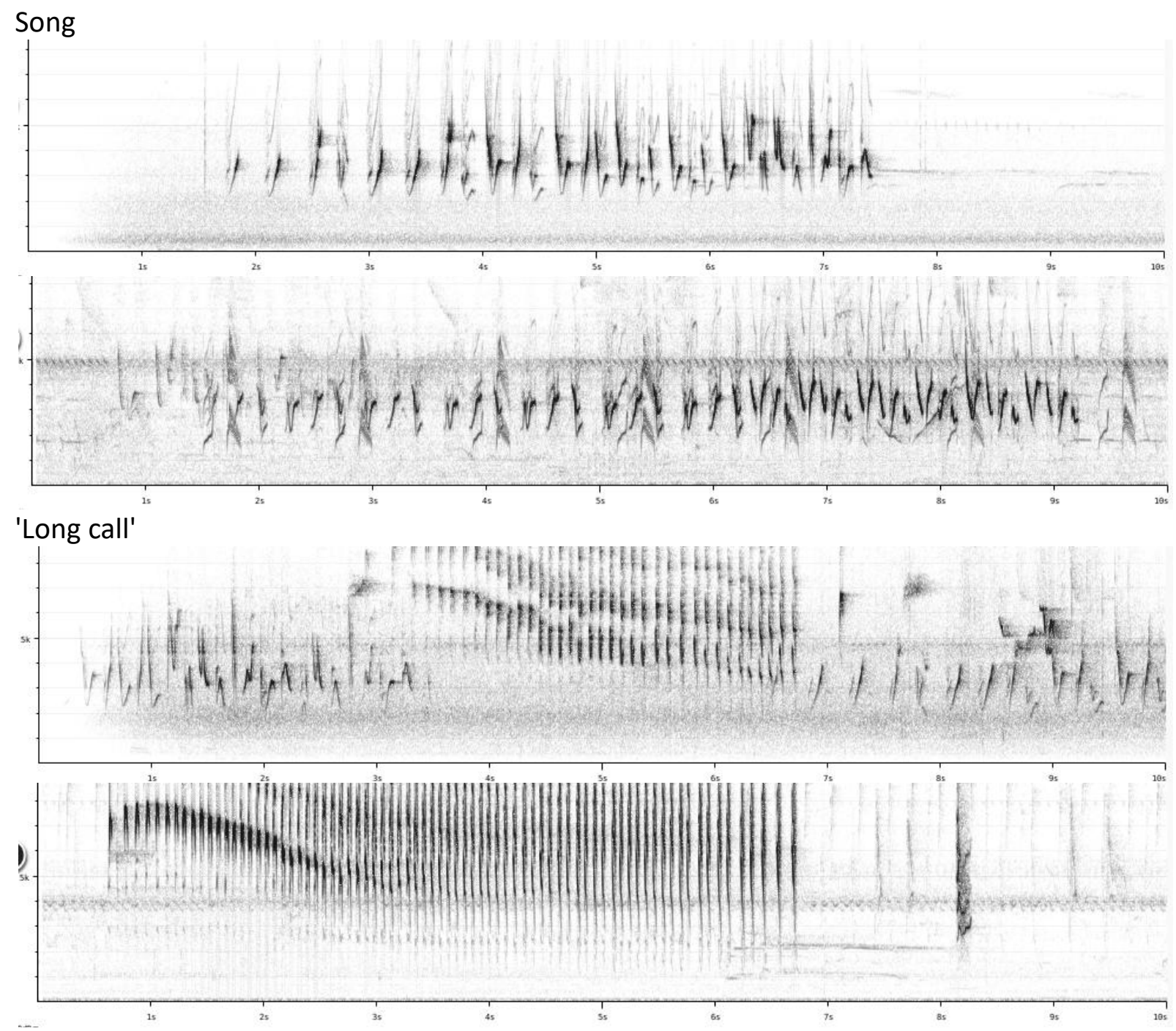

Song starts with a repeated rhythmic phrase "wee..wee..wee-chew" and accelerates into a more varied warble. Duration of the full song is about $6 \mathrm{~s}$ or more.

A peculiar second vocalization (here named 'long call') is a rattle which starts high-pitched and drops to a lower stable level for a prolonged period. 


\section{HANDBOOK OF THE

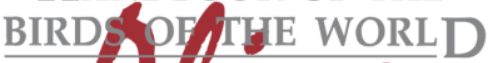 Alve}

\section{ORNITHOLOGICAL NOTES}

G. a. aequinoctialis (N Colombia and Venezuela S to N Amazonian Brazil; also Trinidad) Song
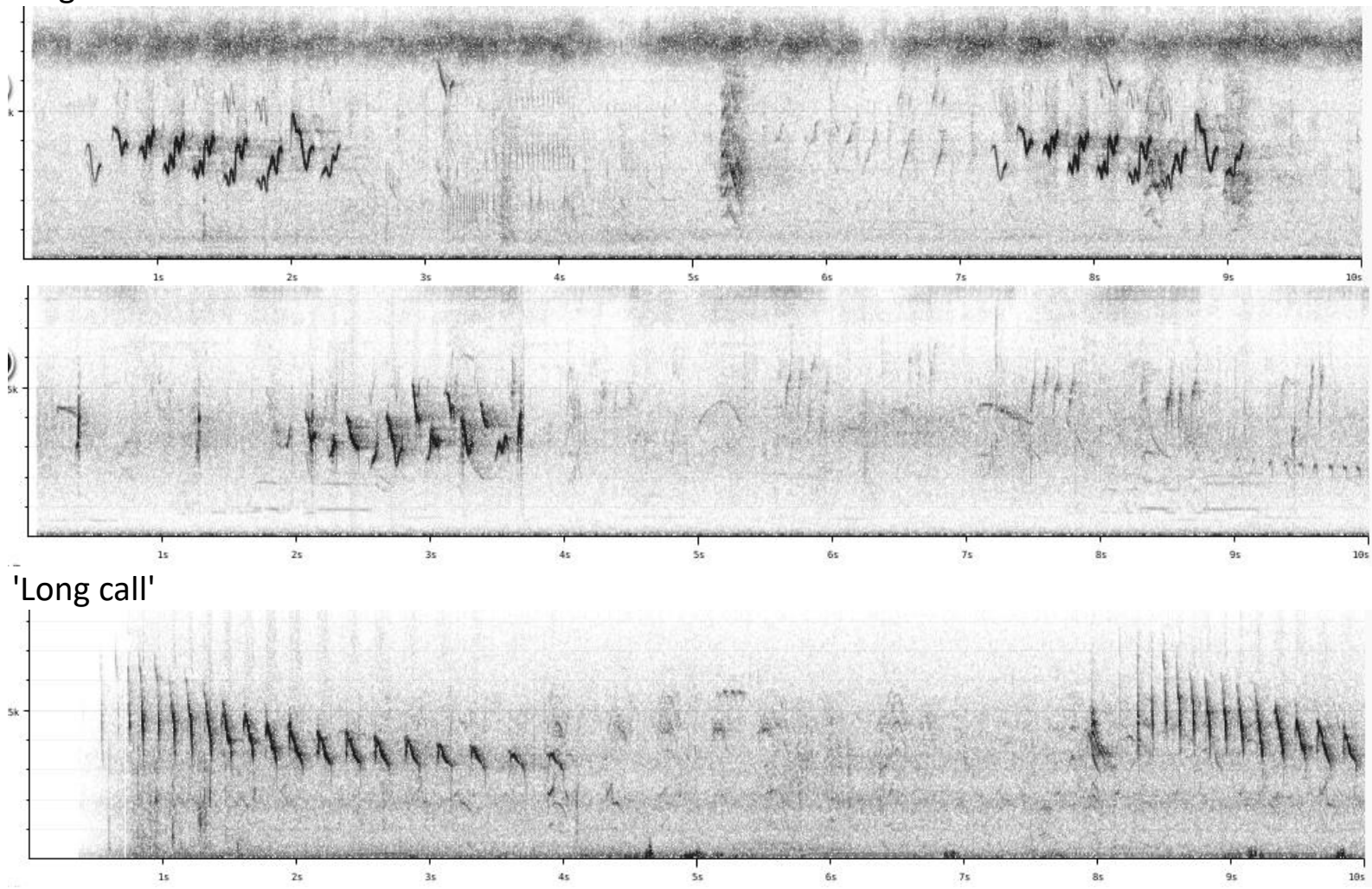

Song is a short sweet warble of about $2 \mathrm{~s}$.

Long call is a melodious descending series of notes.

G. a. velata (SE Peru, N Bolivia and extreme S Amazonian Brazil S to NE Argentina and Uruguay)

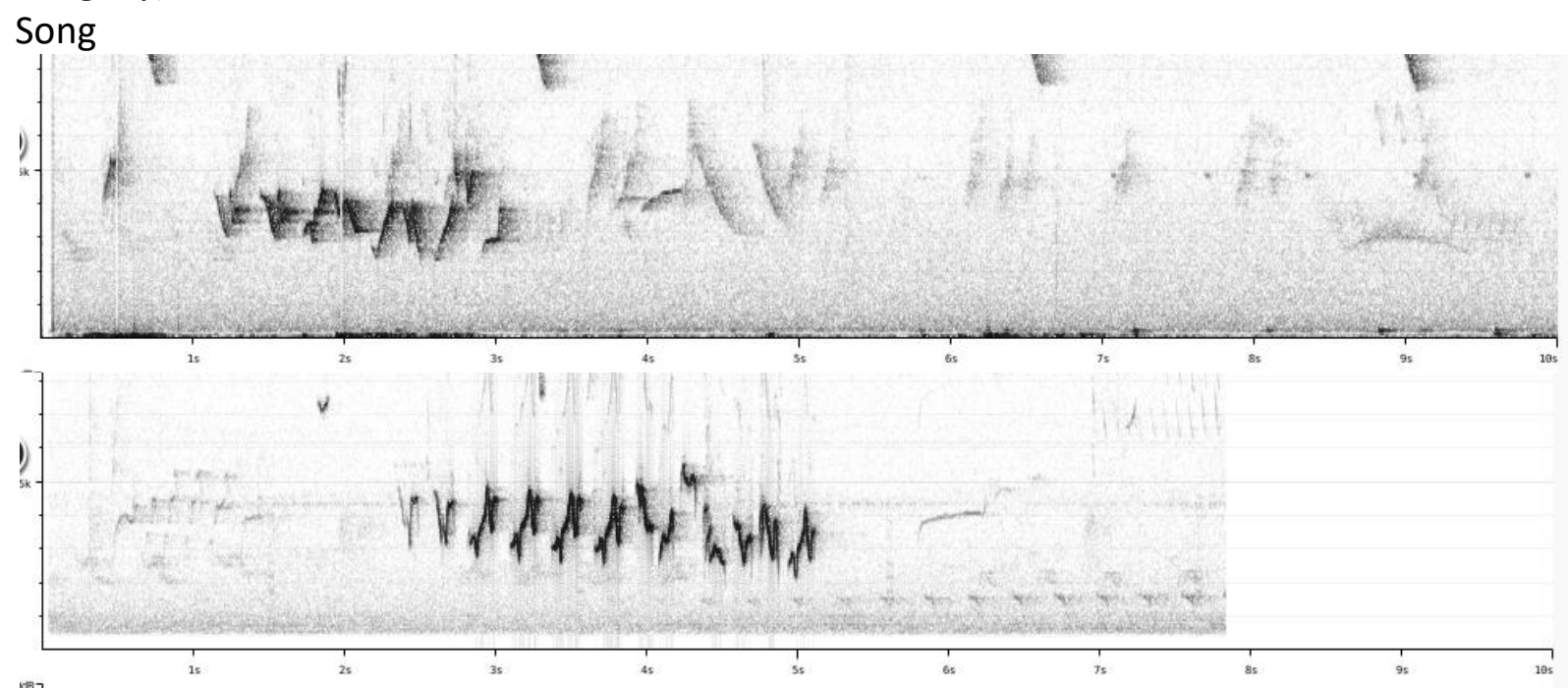




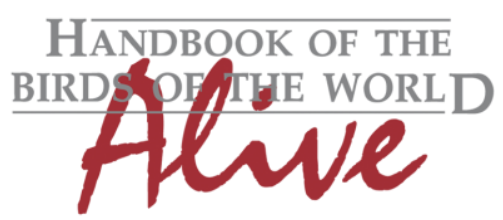

\section{ORNITHOLOGICAL NOTES}

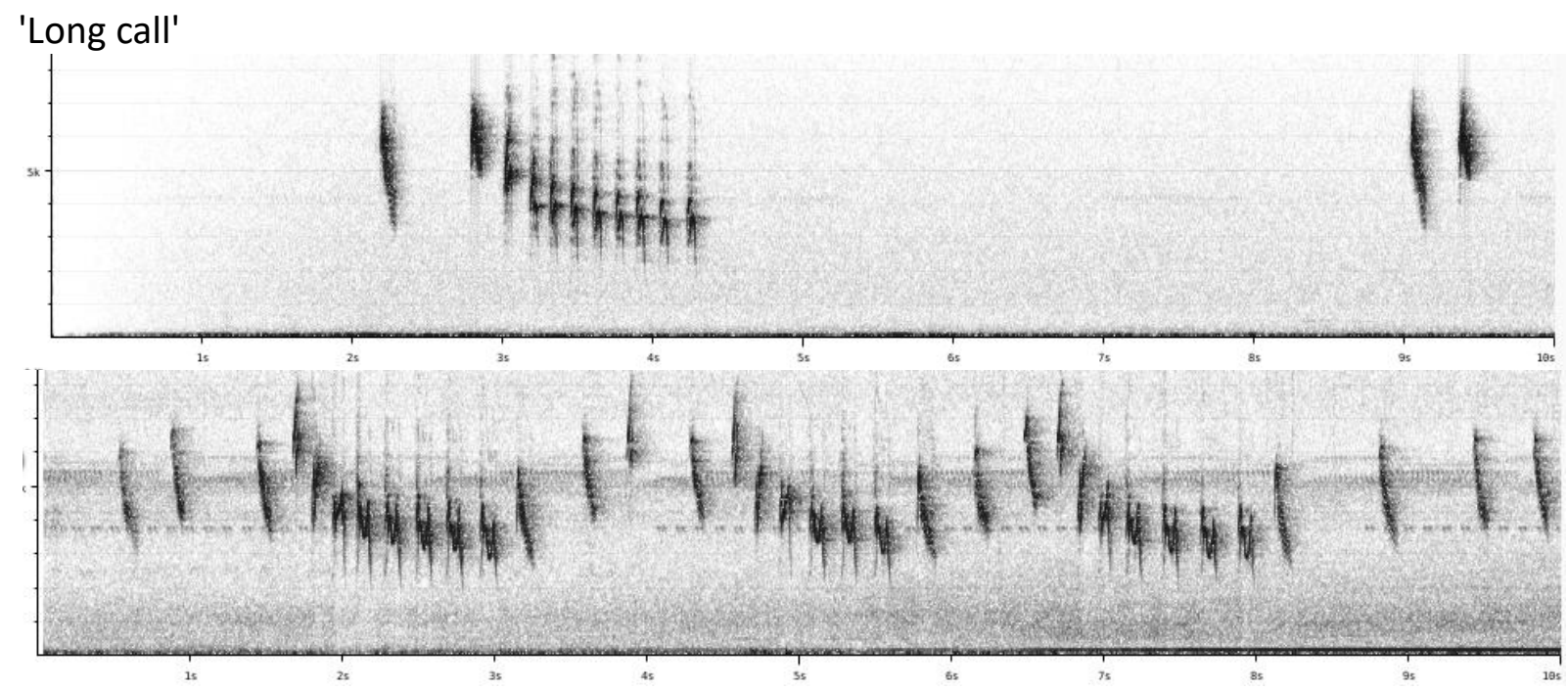

Song a short sweet warble (2-3s), very similar to nominate.

Long call is a descending series of notes (somewhat similar to nominate, but has a very distinct note shape).

G. a. auricularis (Pacific slope of W Ecuador and NW Peru) Song

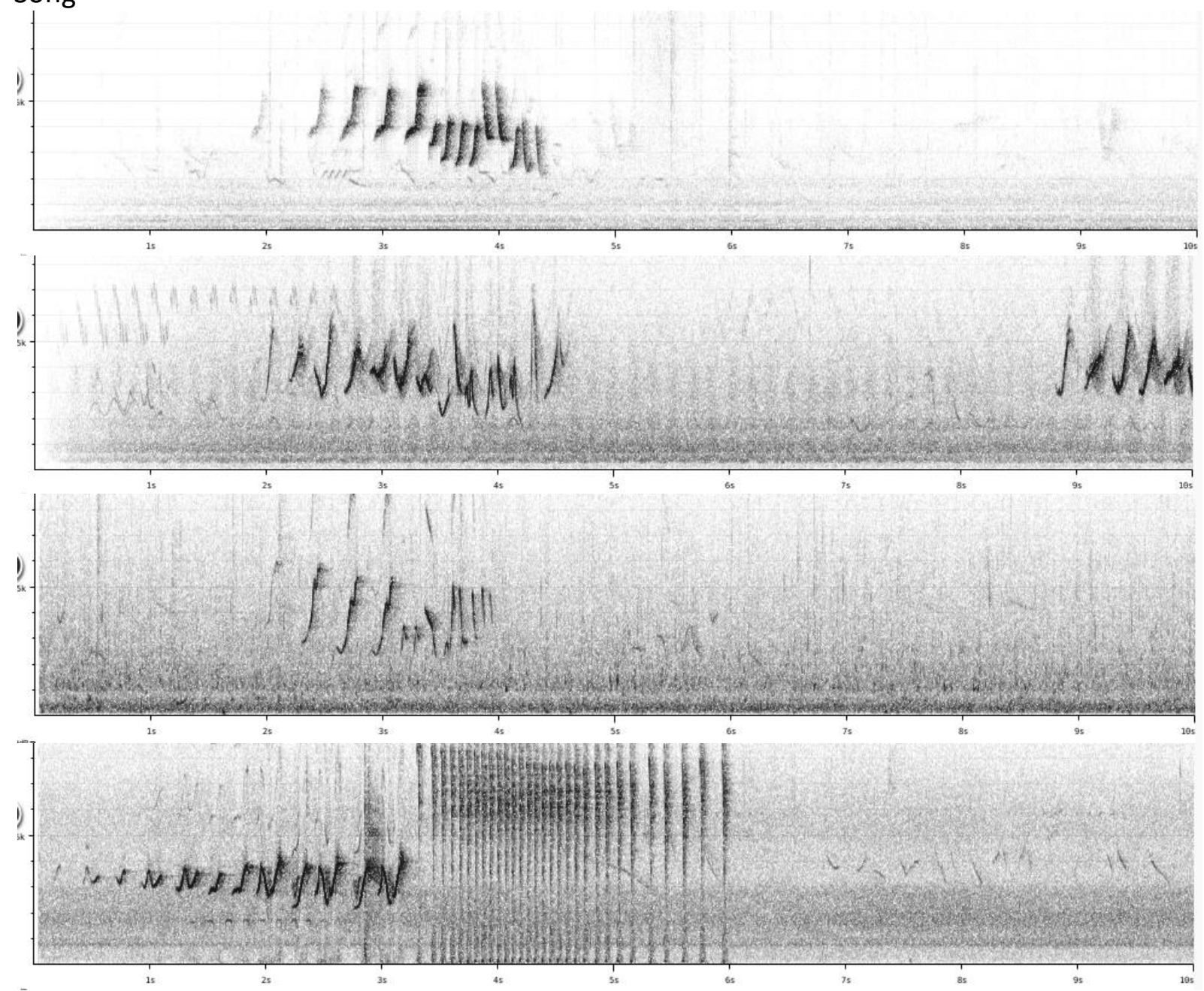




\section{HANDBOOK OF THE \\ winof \\ Alve}

\section{ORNITHOLOGICAL NOTES}

Song a short phrase (2-3s) typically starting with some simple (usually upslurred notes) and rather abruptly shifting to a more warbled phrase (a two parts song).

It is not clear whether the rattle in the last example is of the same species (homologous 'long call')

G. a. peruviana (upper Marañón Valley, in NW Peru (probably also in adjacent SE Ecuador)) Song
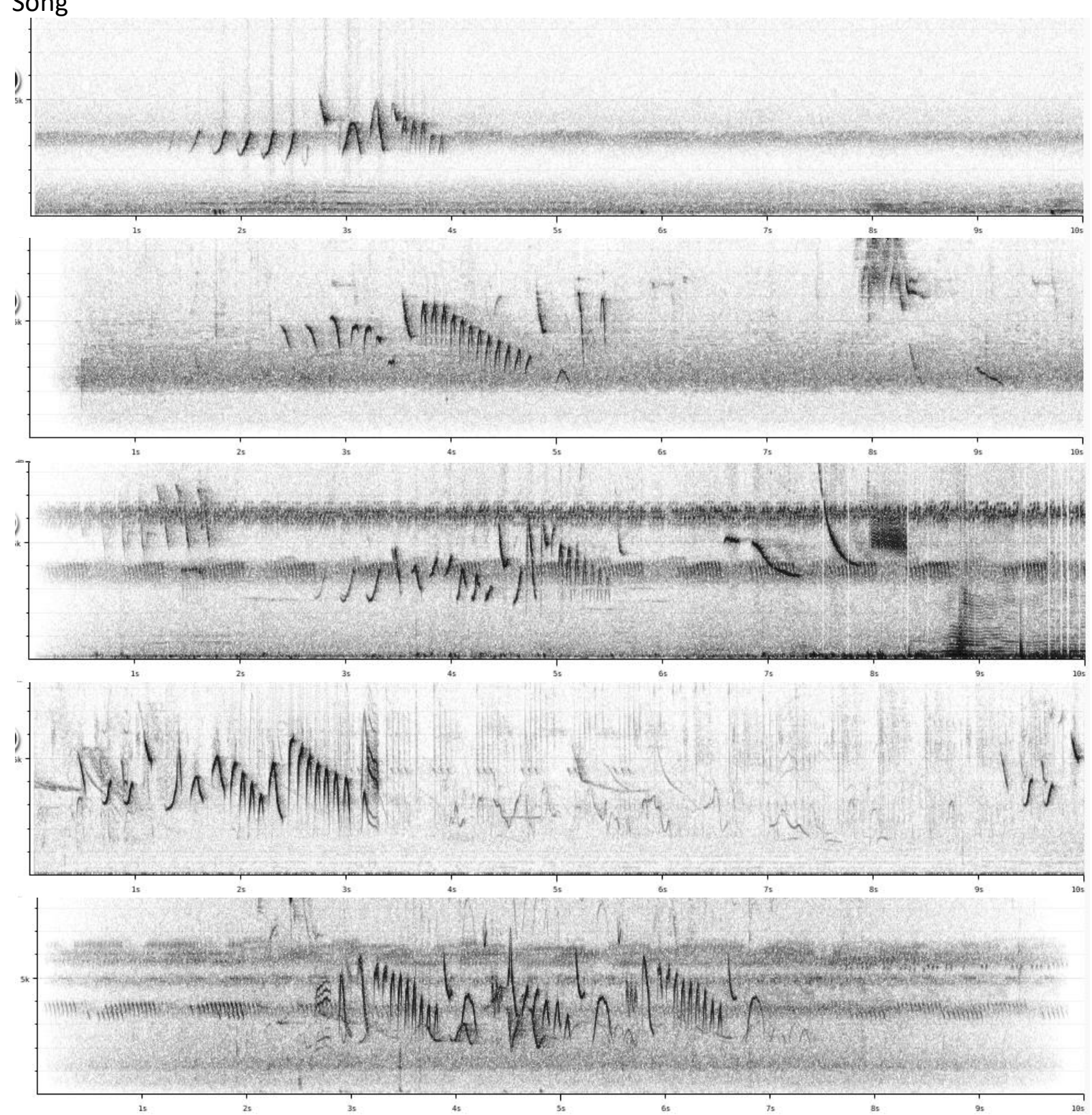

Song is readily recognized by the descending twittering series of notes at the end. First part of the song is closest to auricularis containing mainly simple upslurred or downslurred notes (a two parts song).

Apparently there is no 'long call' equivalent. 

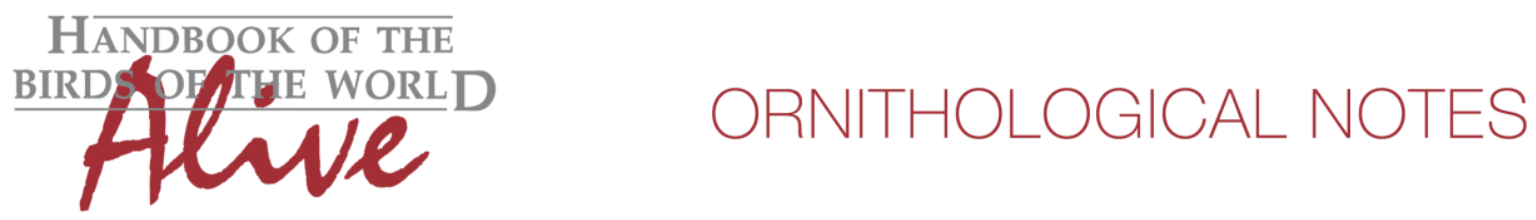

Vocal differences among the various races are thus quite significant:

chiriquensis has a much longer song than any other race (score 3). Song starts with a subphrase repeated several times (unlike any other race, score 2 ) and continues with a gradual acceleration (pace increase, score 2). The long call (or alternative song) is unique, a long fast rattle initially descending in pitch (score 2-3). Total score about 5-6.

Nominate/velata differs from auricularis/peruviana in having a warbled song which lacks two distinct parts (all notes have similar complexity, score 2) and a distinct long call or alternative song which consists of a descending series of notes (score 2). Total score 4.

Nominate differs from velata in having a long call or alternative song which is far less uttered than in velata, with a clearly different note shape (score 2 ).

peruviana differs from auricularis in having a distinct ending to the song, a descending twittered series of (symmetric overslurred) notes (score 2-3).

Calls are seemingly also quite different among the several races, but there aren't enough recordings available at present to draw reliable conclusions.

This note was finalized on 24th June 2016, using sound recordings available on-line at that moment. We would like to thank in particular the many sound recordists who placed their recordings for this species on XC.

\section{References}

Tobias, J.A., Seddon, N., Spottiswoode, C.N., Pilgrim, J.D., Fishpool, L.D.C. \& Collar, N.J. (2010). Quantitative criteria for species delimitation. Ibis 152(4): 724-746.

\section{Recommended citation}

Boesman, P. (2016). Notes on the vocalizations of Masked Yellowthroat (Geothlypis aequinoctialis). HBW Alive Ornithological Note 370. In: Handbook of the Birds of the World Alive. Lynx Edicions, Barcelona. (retrieved from http://www.hbw.com/node/1252920 on 29 November 2016). 